\title{
PANDEMIA, REDES Y SEXUALIDADES: UNA LECTURA CRÍTICA A LOS MODOS DE (DES)ENCUENTRO VIRTUAL
}

\author{
PANDEMIA, REDES E SEXUALIDADES: UMA LEITURA CRÍTICA DOS \\ MODOS DE (DES)ENCONTRO VIRTUAL
}

\author{
Paola Bonavitta ${ }^{1}$ \\ Pascual Scarpino ${ }^{2}$ \\ Luciano Pascual $^{3}$
}

\section{RESUMEN}

Este artículo reflexiona sobre las maneras de vincularse entre personas en un contexto de pandemia global por el COVID-19. Tomamos el caso de la plataforma Grindr y analizamos el mensaje y los usos que propone en el marco del aislamiento social, preventivo y obligatorio que ha decidido el gobierno argentino. Retomando la noción de Industria Cultural que elaboran Theodor Adorno y Max Horkheimer, y las reactualizaciones del concepto que propone Jordi Maiso, indagamos en torno al modo de socialidad que Grindr configura en la actualidad. Desarrollamos la idea de que este tipo de interacción social propuesto no es excepcional, sino más bien una constante en los modos en los que el capitalismo precisa que se configuren las relaciones sociales contemporáneas. Retomando los aportes que el psicoanálisis realiza a la teoría crítica, sostenemos que en el distanciamiento social, en la fractura de los lazos sociales y en la prioritaria mediación de las relaciones a través de la lógica de las pantallas, es posible hallar un malestar.

Palabras-claves: Industria cultural. Pandemia. Sexualidades.

\section{RESUMO}

Este artigo reflete sobre formas de relações entre as pessoas em um contexto de pandemia global pela COVID-19. Pegamos o caso da plataforma Grindr e analisamos a mensagem e usos que ela propõe no marco do isolamento social, preventivo e obrigatório decidido pelo governo argentino. Voltando à noção de Indústria Cultural elaborada por Theodor Adorno e Max Horkheimer, e as atualizações do conceito proposto por Jordi Maiso, investigamos o modo de socialidade que Grindr configura hoje.

\footnotetext{
${ }^{1}$ Doctora en Estudios Sociales de América Latina. Mestra en Sociología. Licenciada en Comunicación Social. Investigadora de Centro de Investigaciones de la Facultad de Filosofía y Humanidades de la Universidad Nacional de Córdoba- CONICET. Directora de El Telar. Comunidad de Pensamiento Feminista Latinoamericano. e-mail: paola.bonavitta@gmail.com

2 Doctorando en Estudios de Género (UNC), Becario doctoral CONICET-UNC, Facultad de Ciencias Sociales (UNC). e-mail: pascual.scarpino@unc.edu.ar

3 Doctorando en Artes (UNC), Becario doctoral SeCyT-UNC, Faculta de Artes (UNC). e-mail: lucianopascual7@gmail.com
} 
Desenvolvemos a idéia de que este tipo de interação social proposta não é excepcional, mas uma constante nas formas em que o capitalismo necessita que as relações sociais contemporâneas sejam configuradas. Retomando as contribuições que a psicanálise faz à teoria crítica, sustentamos que no distanciamento social, na fratura dos laços sociais e na mediação prioritária das relações através da lógica das telas, é possível encontrar um mal-estar.

Palavras-chave: Indústria cultural. Pandemia. Sexualidades.

\section{INTRODUCCIÓN}

Desde la aparición de la pandemia del COVID-19 la humanidad está, cuanto menos, siendo interpelada. Los análisis y proyecciones que han emergido de un tiempo a esta parte sobre las implicancias de esta compleja situación, las preguntas que nos arroja y sus posibles abordajes, han surgido desde distintos campos disciplinares, académicos y activistas. Podríamos comprender que la heterogeneidad de lecturas sobre la cuestión es, en parte, producto de la acentuación que se propone sobre unas u otras dimensiones del problema: aspectos sociológicos, económicos, filosóficos o culturales podrían ser algunos de los que se destacan; sin embargo, e independientemente de la especificidad que decidan poner de relieve, podríamos inferir que todos ellos engendran un carácter eminentemente político, puesto que lo que se cuestiona y sobre lo cual se reflexiona tiene que ver con los modos en que nuestras sociedades se han organizado, las relaciones que éstas han construido con sus entornos vitales y sus efectos.

Este texto se inscribe en ese marco de plurales lecturas, particularizando en algunos nudos articulados que resultan de las inquietudes de quienes escriben. En términos generales, podemos anticipar que la situación de confinamiento, que en Argentina se ha traducido en una política sanitaria a nivel nacional de Aislamiento Social, Preventivo y Obligatorio (ASPO), se constituye como un antes y un después tajante, una bisagra en la experiencia y los modos de socialidad posibles, y se presenta como inédita. Entre los múltiples análisis que pueden hacerse sobre esta situación excepcional que vive el planeta, aquí decidimos indagar en las nuevas formas de socialización -o la resignificación de las ya existentes- que aparecen en el contexto de pandemia global. Tomaremos como caso de análisis a la plataforma Grindr y desde una lectura atenta de la misma buscaremos desarticular los usos a los que ésta convoca, los sentidos 
puestos en juego, y sus implicancias sociales posibles.

No obstante, nuestro interés analítico partirá de comprender a esta situación como la profundización de un modo de interacción vigente que antecede al COVID-19, y no como una entera novedad. Para abordar tal profundización, retomaremos la noción de Industria Cultural que elaboran Adorno y Horkheimer, y las reactualizaciones del concepto que propone Maiso En diálogo con los aportes que el psicoanálisis realiza a la teoría crítica, sostendremos que en el distanciamiento social, en la fractura de los lazos sociales y en la prioritaria mediación de las relaciones a través de la lógica de las pantallas, es posible hallar un malestar.

Concluimos resaltando lo que, desde un comienzo, ha alimentado la inquietud por pensar y abordar el problema planteado: los individuos, en el marco del entero proceso social, nunca resultan íntegramente cosificados. Por el contrario, por más reificación que el sistema social produzca, el individuo aloja un malestar que nos permite pensar otros escenarios de interacción social y afecciones posibles. Volveremos sobre esta idea para presentar algunas preguntas que nos permitan imaginar un escenario diferente post COVID-19.

El artículo se estructura bajo el siguiente orden. En primer lugar, presentaremos el marco conceptual desde el cual abordamos el tema en cuestión. En un segundo momento nos centraremos específicamente en la plataforma Grindr ${ }^{4}$ y los usos que propone en la ciudad de Córdoba, Argentina, en el marco de la actual pandemia; por último compartiremos algunas aproximaciones sobre los interrogantes que el problema nos arroja así como sus posibles abordajes.

\section{INDUSTRIA CULTURAL: EL ENGAÑO DE LO NOVEDOSO Y LA LÓGICA PORNOGRÁFICA}

El diagnóstico que elaboran Theodor Adorno y Max Horkheimer en Dialéctica de la

\footnotetext{
${ }^{4}$ Es una plataforma que nace en 2009 y está destinada a varones gays y bisexuales. La aplicación muestra en forma de mosaico las fotografías de los usuarios, y permite ver su cercanía geográfica (geosocial), y el perfil del usuario. Tiene la posibilidad de chatear, enviar fotografías privadas, o dar la ubicación exacta de otros usuarios (localización GPS). Actualmente está disponible en 192 países.
} 


\section{Revista \\ Debates Insubmissos}

Ilustración, específicamente en el capítulo sobre industria cultural, logra describir el estadio de la cultura en una era totalitaria y, al mismo tiempo, dar cuenta de su relación con la situación de una subjetividad debilitada. La cultura, ahora producida a partir de lógicas industriales, organiza cada vez más nuestra vida interna y externa, diseña los modos en los que reconocemos y buscamos satisfacer nuestros deseos más íntimos, ordena los tiempos de producción y de compensación de la energía invertida en el trabajo, los tiempos de la diversión y el placer. Así lo leyeron a principios de los años cuarenta, luego de haber sido testigos de los modos en los que el nascismo ascendió al poder político y luego, durante el exilio en Estados Unidos, haber trabajado y permanecido en profunda cercanía con las lógicas de producción del entretenimiento y de la radiodifusión.

Adorno y Horkheimer lograron construir aquellos lazos que vinculan lo aparentemente antagónico: la industria del entretenimiento y el fascismo. Supieron mostrar las lógicas por las cuales ambas podrían caracterizarse como expresiones totalitarias, un totalitarismo que sin embargo utilizaba el engaño y las fuerzas más profundas del sujeto para sostenerse girando en un círculo vicioso. Son diversos los y las pensadoras de nuestro tiempo que reconocen los aportes de la escuela de Frankfurt y cómo estos resuenan en las experiencias y formas de vida de nuestro presente. Sin embargo, y a los fines de este trabajo, además de retomar ciertos planteos centrales de la obra de los teóricos críticos, también nos interesará abordar la reactualización de la noción de Industria Cultural que realiza Jordi Maiso.

\subsection{Industria cultural en los teóricos críticos}

La tesis que sostienen Adorno y Horkheimer, como referíamos anteriormente, en el capítulo "Industria Cultural. Ilustración como engaño de masas", es que la sociedad presenta a sus elementos como un todo integrado, distanciandose de aquellas tesis que afirmaban el carácter caótico, desinteresado y espontáneo de la cultura de su momento. El tiempo libre, que podríamos haber caracterizado como 'lo otro' del trabajo, en la era capitalista se estructura como condición necesaria para éste. El tiempo libre y la diversión que podríamos encontrar en él, se revela como "la prolongación del trabajo bajo el capitalismo tardío" (ADORNO y 
Revista

Debates Insubmissos

HORKHEIMER, 1998, p. 181). No sólo es el tiempo en el que recuperamos la energía para volver al trabajo, sino también, es el tiempo en el que gastamos el dinero en busca de diversión y placer, manteniendo la demanda de los productos, justificando así la producción de los mismos. Finalmente señalan que las lógicas exigidas en el tiempo de trabajo dejan huella en la subjetividad de los sujetos, y son estas mismas lógicas las que vuelven a ser exigidas como condición necesaria para la diversión. Los autores plantean que "El supuesto contenido, no es más que una fachada; lo que deja huella realmente es la sucesión automática de operaciones reguladas. Del proceso de trabajo en la fábrica y en la oficina sólo es posible escapar adaptándose a él en el ocio" (ADORNO; HORKHEIMER, 1998, p. 181).

Con ello señalan las implicancias económicas y políticas de la división de los modos, los tiempos y los espacios para el placer. La estructuración inquebrantable de los tiempos y la repetición mecánica de las operaciones se introyectan en la subjetividad incidiendo en las formas mismas de la sensibilidad, pactando de antemano cómo se establecerán las relaciones entre los sujetos, sus deseos y las mercancías.

Los autores describen también las consecuencias del entero proceso de socialización, el cual llega a penetrar en las fibras íntimas de los sujetos, un proceso de manipulación de la vida interna que se corresponde con las necesidades de la vida externa: "Dado que la incorporación de todas las tendencias de la industria cultural en la carne y la sangre del público se realiza a través del entero proceso social, la supervivencia del mercado en este sector actúa promoviendo ulteriormente dichas tendencias" (ADORNO y HORKHEIMER, 1998, p. 181). Pero se desmarcan inmediatamente de las lecturas marxistas deterministas del mero "reflejo ideológico" para señalar que la identificación del individuo con la totalidad social nunca puede llegar a ser total. Son las cicatrices generadas en el intento de la integración social las que permiten una movilización ideológica posterior a través de falsas gratificaciones. A estas cicatrices Adorno y Horkheimer (1998) también las denominan "pequeñas callosidades" (p. 303) cuyas superficies se han vuelto insensibles, haciendo referencia a un proceso de endurecimiento subjetivo, de pérdida de sensibilidad, que en la etapa totalitaria del capitalismo se desarrolla como un entero sistema de cicatrices (Adorno, 2004 p. 23). En definitiva, el malestar que no se resuelve, da cuenta de la imposibilidad de una identidad total entre el 
individuo y la sociedad mostrando así los límites de la alienación total.

En este trabajo nos interesa mantenernos en la tensión de estos dos momentos de la crítica: por un lado aquella lectura que permite reconocer que los estándares que construye la industria cultural son introyectados en y por los sujetos al punto de dar forma a la experiencia de manera anticipada; y por otro, reconocer que dicha planificación de los deseos más íntimos tiene su límite en tanto que existe un sustrato libidinal, aunque sí manipulable, no alienable en los sujetos. Los límites del intento civilizatorio necesitan mostrarse en su profunda implicación con los sujetos como en su diferencia. Aquí la libido puede ser parcialmente comprometida con fines heterónomos, pero esto no implica su desaparición ni su mera subsunción al sistema.

Si esta co-implicancia entre los individuos y la sociedad no permite una reificación total de los sujetos, resulta interesante reconocer cuáles son aquellos mecanismos por los cuales hay una reincidencia y un sostenimiento de las lógicas del sometimiento, que Adorno y Horkheimer llegan a caracterizar como masoquistas (1998, p. 184). El constante atractivo de la industria cultural al que se deja llevar el sujeto, se vincula precisamente con aquella organización a priori de la experiencia y de las formas en las que se debe buscar satisfacer el deseo. Y este mecanismo sólo se mantiene en constante funcionamiento por lo que describen los autores como la "ley suprema”, la cual consiste en que quienes "disfrutan de ella no alcancen jamás lo que desean, y justamente con ello deben reír y contentarse" (ADORNO; HORKHEIMER, 1998, p. 186).

La satisfacción de todas las necesidades es fundamentalmente una promesa, no una realidad, y la aspiración de dicha satisfacción permite la movilización de las fuerzas internas del sujeto. "Ofrecer a tales víctimas algo y privarlas de ello es, en realidad, una y la misma cosa. Éste es el efecto de todo el aparato erótico. Justamente porque no puede cumplirse jamás, todo gira en torno al coito" (ADORNO; HORKHEIMER, 1998, p. 186). A esta dinámica particular proponemos comprenderla bajo el concepto de lógica pornográfica. Por su parte, la idea de coito podemos entenderla como una satisfacción total del deseo, la consumación del mismo. Más útil nos puede llegar a resultar aquella imagen a la que refieren cuando señalan que nunca se otorga aquello mismo que se pide, más bien "el huésped debe contentarse con la lectura de la carta de menús" (ADORNO; HORKHEIMER, 1998, p. 184). 


\subsection{El lugar del psicoanálisis en la Teoría Crítica}

En este sub-apartado, tomamos los aportes de Jordi Maiso en torno a la apropiación que la Teoría Crítica realizó del psicoanálisis. Este autor nos propone desarticular las distintas vertientes que se condensan en la teoría crítica, para recuperarlas desde sus vinculaciones con el psicoanálisis. En este marco, el autor retoma que existe un diagnóstico según el cual determinados aportes del psicoanálisis y la teoría crítica han sido sepultados a partir de la fragmentación de sus contenidos por diversas tradiciones. Tal como recupera Maiso (2013), Detlev Claussen propone que la sociología, la filosofía, la medicina, la psicología, o la comunicación, por ejemplo, han tomado de ambas teorías sólo los aspectos que consideraron significativos en función de sus objetos de estudio particulares (MAISO, 2013 p. 133). Esto ha provocado un desdibujamiento de los fundamentos y objetivos que aquellas teorías sostenían. Tal situación ha convocado el interés de Maiso por volver la mirada sobre aquellos textos y conceptos fundamentales, y repensar rigurosamente su vigencia a la luz de ciertos procesos contemporáneos.

En su artículo La subjetividad dañada (2013), Maiso vuelve la mirada sobre los problemas planteados al interior de la teoría crítica y del psicoanálisis, que no han sido retomados por las generaciones que las sucedieron; el autor entiende que a lo largo de los años, ambas teorías no solo han sido reapropiadas fragmentariamente, sin asumir la complejidad de sus problemas aún abiertos, sino que además, han desconocido los elementos centrales que las constituían como herramientas críticas. Por ello, en el marco de una reactualización de su vigencia, se constituye como un ejercicio necesario asumir la responsabilidad del abordaje de sus problemas irresueltos.

A partir de la revisión que el autor realiza entendemos que, en el desarrollo de la teoría crítica, se incorporaron aportes del psicoanálisis con el objetivo de enriquecer la comprensión de lo que en términos de Adorno podemos referir como "las condiciones subjetivas de la irracionalidad objetiva" (ADORNO, 2004, p. 42). Es decir, frente a los acontecimientos sociales 
de la época como el ascenso del fascismo, los miembros del Institut ${ }^{5}$ realizaron una apuesta por incorporar la complejidad interna del sujeto como un factor fundamental en la creación y sostenimiento de esa objetividad social. Los trabajos de estos autores permiten explicar cómo los sujetos se vuelven activos en la reproducción de la violencia, el terror y la coacción social, incluso cuando tales conductas funcionan como una falsa resolución de un malestar subjetivo. Quizás la mayor apuesta de la escuela de Frankfurt radica en volver a ubicar al sujeto y su consciencia, ya no como mero reflejo de una estructura social determinante, sino como un elemento fundamental en una relación dialéctica con la realidad objetiva. Es decir, lo que teoría crítica de la sociedad y psicoanálisis en su abordaje conjunto permitirían comprender, es "la dialéctica entre civilización y naturaleza en el proceso social de domesticación de los seres humanos" (MAISO 2013, p. 138).

Para Maiso, la contribución del psicoanálisis debe buscarse en torno a la comprensión de los conflictos psíquicos. Retomando el aporte de Freud, el autor entiende que estos se originan en torno a la constitución del Yo, donde se encuentra a su vez la posibilidad de leer las huellas de la dominación en los efectos que produce el choque entre el principio de placer y el principio de realidad. En esa tensión entre lo que el individuo atraviesa en relación a la búsqueda de la gratificación, y la coacción social que se le impone como límite real, se halla la génesis del Yo. A través de su estudio, el psicoanálisis permitió entonces evidenciar el reverso oculto en la configuración del Yo, al tiempo que reconocer que la historia misma de la civilización en su conjunto, es una historia de represión y renuncias. En este marco, para la escuela de Frankfurt, el psicoanálisis se presentaba como una herramienta privilegiada para comprender las huellas materiales que la dominación inscribía en los sujetos y la sociedad. A diferencia de otros aportes teóricos, a su vez, retomar a Freud permitía correrse de un análisis sociologizante de los procesos sociales, e inscribirse en una lectura dialéctica en la cual confluyen las dimensiones subjetivas como objetivas de la dinámica social. En síntesis, en palabras de Maiso (2013)

En un momento en que el fascismo y el antisemitismo se difundían en las sociedades

\footnotetext{
${ }^{5}$ El Institut für Sozialforschung fue fundado en 1923 y fue sede institucional de la denominada Escuela de Frankfurt de la cual formaron parte, entros pensadores, Max Horkheimer, Theodor Adorno y Walter Benjamin.
} 


\section{Revista \\ Debates Insubmissos}

supuestamente más 'civilizadas' sin encontrarse con apenas resistencias, la Teoría Crítica descubrió en el psicoanálisis freudiano un aliado imprescindible para entender la génesis de la 'falsa conciencia' en la psique individual y las razones de la persistencia de una brutalidad 'arcaica' en el seno de una civilización supuestamente hipermoderna. (MAISO, 2013, p. 140).

Esa brutalidad arcaica, según el psicoanálisis, resultaba de una escisión cada vez mayor entre la vida interna y la vida externa de los individuos. Es decir, implicaba el enfrentamiento y la asunción de la dificultad cada vez más profunda, de la imposibilidad cada vez mayor de hacer coincidir la satisfacción de los intereses y necesidades de los individuos, y las exigencias sociales que garantizaban la supervivencia en común.

Por tanto, si esa escisión se vincula con la brutalidad de la sociedad, y por ejemplo da cuenta o permite explicar en cierta medida la emergencia del fascismo, cabría preguntarse qué sucede en sociedades donde hay una mayor restricción de posibilidades de la satisfacción de deseos, y donde resulta cada vez más insalvable la brecha entre los deseos de los individuos y una realidad cada vez más coactiva. $\mathrm{O}$ en los términos que convoca nuestro interés particular de este artículo, cómo podríamos comenzar a aproximarnos a una lectura en proceso de ciertas reacciones sociales frente a la reactualización de esas insatisfacciones en el marco del confinamiento obligatorio.

Adorno y Horkheimer comprendieron en su momento que era necesario repensar la idea freudiana de cicatriz narcisista. Ésta refería a la herida en la autoestima producida por la renuncia que implicaba el proceso de socialización en el individuo y con ello, la génesis del Yo. Acompañaba a este proceso de constitución subjetiva un malestar, una necesaria renuncia y un sentimiento de inferioridad. A diferencia de la época en la que Freud escribió, caracterizada por los teóricos críticos como la "Era liberal-burguesa", comprendieron que los problemas de su tiempo se estaban produciendo en el marco de lo que definieron como una "Era Totalitaria", en la cual las coerciones sociales eran experimentadas de manera violenta, abruptas, a la vez que reproducían una sociedad con cada vez más exigencias de renuncias subjetivas (MAISO, 2013, p. 143). Esta nueva Era implicaba otros desafíos para el pensamiento crítico. Ese desplazamiento epocal significaba a su vez una refuncionalización de los procesos de introyección de las normas y sus implicancias en los individuos y la sociedad. En este sentido, la propuesta de cicatriz narcisista es actualizada con la noción de sistema de cicatrices, la cual 
posibilita abordar la configuración de una subjetividad debilitada que se experimenta como tal en el marco de los procesos que la Era Totalitaria le presenta al individuo. De este modo, como aclara Maiso: "El paso de la 'cicatriz narcisista' freudiana al 'sistema de cicatrices' revela la transición a una sociedad cada vez más marcada por la heteronomía, que impone a los individuos una ratio brutal fundada sobre la angustia y el miedo.” (MAISO, 2013, p. 142)

Frente a las necesidades y deseos que el sujeto lleva consigo, y al dolor causado por el distanciamiento recrudecido entre su vida interna y los condicionamientos de la vida externa, emerge la falsa conciencia como una respuesta que posibilita la adaptación del sujeto. Ello sucede ofreciendo satisfacciones sustitutivas que buscan mitigar aquel dolor experimentado, sin faltar a las demandas que el principio de realidad le plantea. Es decir, esta angustia que atraviesa el individuo frente a la sistemática renuncia, precisa de una compensación que será organizada a través de los mecanismos de la falsa conciencia (MAISO, 2013, p. 142).

Atento a los procesos sociales vigentes, Maiso entiende que Adorno ve en ciertas formaciones sociales la cristalización de una parte del funcionamiento de la compensación al narcisismo herido que los individuos enfrentan. Centrado en el antisemitismo, el pensador entendía que allí operaba un "medio de masas", que implicaba la inscripción de individuos en grupos (es decir, masas) bajo la figura de un líder (en este caso, el führer). Estas instancias serían "medios de masas" en tanto al provocar la movilización de sentimientos, conflictos e impulsos inconscientes (en lugar de promover su paso consciente y aclararlos), los individuos aislados se conectan entre sí a través de un vínculo libidinal originado en el resentimiento. En esta movilización de impulsos inconscientes, continuando con el estudio que realiza Maiso, la ideología trabaja ofreciendo contenidos precisos que reemplacen y posterguen el abordaje consciente de tales conflictos. De este modo, el entramado de los mecanismos de dominación social se alimenta de los aspectos irresueltos de los individuos -que son las fuentes primarias de su malestar, sus heridas narcisistas-, y proponen respuestas sustitutorias a través de la operación de desplazamiento y condensación; las mismas pueden ser comprendidas como falsas curaciones. Por tanto, no es el contenido mismo de la ideología donde se debe construir la crítica, sino en el mecanismo a través del cual ella opera. En este sentido, la idea y el contenido del discurso ideológico son intercambiables, pues su fin es el de justificar la descarga de la 
agresividad que la interiorización de las coerciones sociales ha sedimentado en los individuos.

Ahora bien, ¿por qué estos aportes que aparecerían en cierto sentido tan distantes de los problemas contemporáneos, pueden ser considerados como claves de lectura para analizar el contexto del confinamiento actual? Pues porque entendemos, tal como hemos presentado hasta el momento, que la noción de industria cultural nos trae consigo la posibilidad crítica de comprender como engañoso aquello que se presenta como novedoso, divertido y placentero. En particular, en el contexto pandémico de COVID-19, esto puede ser analizado especialmente en los usos y prácticas que se ven enfatizados y convocados a experimentar en el marco de la plataforma Grindr. El carácter pornográfico de esta plataforma no se entenderá a partir del contenido de las imágenes, sino en las formas en que la aplicación media las relaciones entre los sujetos, los deseos y las mercancías. Es decir, pornográfico será para nosotros el modo sistemático en el cual se ofrece la promesa de consumación del deseo, pero al mismo tiempo se suspende y aplaza la misma: en definitiva la plataforma ofrece a sus usuarixs sólo la carta de los menúes.

En este sentido, analizando los desplazamientos y condensaciones que aparecen para suplir ciertas necesidades, consideramos que podremos leer algunos malestares que emergen a partir de ello. Si la industria cultural nos permite pensar críticamente que todo cuanto acontece en el marco del sistema capitalista en la fase actual de su desarrollo es resultado de una sistemática promesa incumplida, cabría preguntarse entonces ¿qué es lo que buscamos cumplir a través de nuestra inmersión digital que, minuto a minuto, parece colonizar cada vez más dimensiones de nuestra vida? Si las interacciones sociosexuales construidas a partir de la plataforma Grindr pueden ser leídas en algún sentido como un posible engaño, nos podría convocar al interrogarnos ¿qué es lo que se encuentra velado allí, lo que se oculta y lo que no podrá cumplirse?

\section{LA VIDA VIRTUAL COMO UN ENGAÑO}

Como indicamos al comienzo, el contexto de aislamiento social y confinamiento establecido en numerosos países frente al desarrollo del COVID-19, implica determinados 
desafíos. Los modos de readecuación e intento de continuación de buena parte de la vida cotidiana han implicado, para ciertas capas poblacionales, el sostenimiento de las mismas actividades a través de otras plataformas virtuales. Son las experiencias del teletrabajo, la educación virtual, o la compra de productos y servicios a través de las pantallas las que rápidamente pueden identificarse en alza. Pero, de igual modo, el sostenimiento de lazos familiares, amistosos o vinculos sexoafectivos mediado por plataformas virtuales, demuestran que la "nueva" socialidad a la que nos arroja este estado de excepción ha cobrado un rol sustancial en el día a día. En el caso particular de la ciudad de Córdoba ${ }^{6}$, la cuarentena preventiva obligatoria comenzó a regir el 20 de marzo de 2020. Desde ese momento, se resignificaron las maneras de vincularse entre las personas y hubo una especie de reinvención de los encuentros. En lo que respecta a las plataformas de citas, no podemos hablar de una completa novedad frente al aislamiento por el COVID-19 pues estas app (como Tinder, Happn, Grindr, Growlr, entre otras) llegaron para quedarse hace alrededor de una década. No obstante, su formato implicaba un conocimiento virtual que derivaba en un posible encuentro personal. ¿Qué sucede en pandemia y con aislamiento preventivo obligatorio? ¿Qué ocurre en una ciudad donde la policía controla los pasos y apresa a quien circula sin permiso?

Lo que antes se presentaba como un medio para convocar al encuentro, es decir, la pantalla, ahora es el todo de la interacción, y aparentemente no queda nada por fuera de ella. En la pantalla nos vemos a nosotrxs mismxs; el ojo que nos mira es el propio, y así la imagen traducida en dos dimensiones, digitalizada, inmaterial, viene a representarnos frente a lxs otrxs y frente a nosotrxs. También vemos la imagen que construimos de nosotrxs en el momento en que sucede: la inmediatez de la propia experiencia visual con unx mismx. Pero insistiendo en el eje que vertebra nuestra reflexión, el confinamiento es, en un sentido, una constante más que una excepción: la reclusión se presenta a los ojos de quien la observa rápidamente, como un momento excepcional. Pero cabría preguntarse en qué términos, el imperativo del confinamiento no es sino en verdad el modo privilegiado a partir del cual la industria cultural puede operar en las sociedades 2.0 (DUARTE, 2011): se necesitan subjetividades dañadas que

\footnotetext{
${ }^{6}$ Córdoba es la segunda ciudad más importante de Argentina, con población de 1329604 habitantes.
} 
adhieran a la oferta de consumos que la fase actual del capitalismo propugna, y ellas pueden realizarse si, y sólo si, el lazo social del individuo con su entorno está en un sostenido “cortocircuito estable" (MAISO, 2013 p. 144).

En el terreno de las sexualidades, ya han sido noticia a escala internacional las "sexparties" y "orgías virtuales" popularizadas en distintos países a través de plataformas como Zoom, Skype o FaceTime ${ }^{7}$. De manera creciente, los sexshops online en distintos lugares del mundo han visto agotados sus stocks de productos, e incluso diferentes gobiernos han emitido comunicaciones oficiales en donde se recomienda el sexting o la masturbación antes que el encuentro con parejas sexuales con las que no se esté conviviendo para prevenir posibles propagaciones del virus SARS-CoV-2 ${ }^{8}$. En el mismo sentido, algunos estudios indican el aumento no sólo de descargas de aplicaciones de citas o consumo de pornografía a través de páginas web, sino también el uso más prolongado de las mismas ${ }^{9}$. Para algunos, esta escalada de descargas de aplicaciones de citas como Grindr resulta paradójico: en un contexto donde la posibilidad del encuentro está vedado por las prerrogativas del confinamiento en el marco de una cuarentena, estas aplicaciones evidencian un mayor uso y llegada a nuevxs usuarixs, aún cuando es sabido que -en términos generales- el encuentro físico no podrá concretarse. ${ }^{10}$

Sin embargo, tal como planteábamos, nos permitimos sospechar de que esta situación resulte paradojal. Lo que en buena medida se presenta en este momento como inédito en torno a los modos de vincularnos, podría ser en realidad apenas la profundización de ciertos modos

\footnotetext{
${ }^{7}$ Para conocer sobre la cuestión puede interesar la nota "Gracias al coronavirus, las fiestas sexuales y las orgías virtuales se están popularizando", disponible en el portal web Mor.Bo https://www.ismorbo.com/gracias-alcoronavirus-las-fiestas-sexuales-y-las-orgias-virtuales-se-estan-popularizando/

${ }^{8}$ Sobre las recomendaciones del Ministerio de Salud argentino en torno al sexo virtual y la masturbación para prevenir contagios, ver "Las pautas para tener relaciones sexuales seguras en medio de la pandemia" https://www.pagina12.com.ar/260318-el-ministerio-de-salud-recomendo-el-sexo-virtual-y-el-sextin

${ }^{9}$ El estudio realizado por Smartme Analytics sobre el "Impacto del Coronavirus en el móvil de los españoles según grupos de edad" da cuenta de que entre jóvenes menores de 35 años, el uso de apps como Grindr, Tinder, Badoo y Wapo ha aumentado en un $24 \%, 94.4 \%, 52.4 \%$, y $34.9 \%$ respectivamente, desde que comenzó el estado de confinamiento. Para más información: https://www.smartmeanalytics.com/product_detail.php?id_prod=2\&id_report=9

${ }^{10}$ Reina, Laura (9 de abril de 2020) "Flirteo virtual: el paradójico auge de las apps de citas en pleno aislamiento" https://www.lanacion.com.ar/politica/flirteo-virtual-paradogico-auge-apps-citas-pleno-nid2352664
} 
Revista

Debates Insubmissos

ya existentes de interacción social, y particularmente, sexual en nuestra época.

\subsection{Grindr: la máscara como límite de la interacción}

Ahora bien, ¿qué podemos decir sobre el tipo de socialidad que plataformas como Grindr nos arrojan? En primer lugar, si sostenemos la idea de que la industria cultural se hace carne y se hace sangre en los sujetos, a través del entero proceso social, y que la sucesión automática de operaciones reguladas imprime una huella en el sujeto (ADORNO y HORKHEIMER, 1998, p. 181), podemos analizar a las redes sociales como un espacio en el cual se propicia un modo de interacción que propone inscribir en las subjetividades ciertas formas de vincularse como "naturales". El Otro aparece como tal en función de que el usuario desee que aquél aparezca. Aún cuando emerge independientemente del propio deseo (una imagen que circula e intrépidamente se cuela en la propia mirada), es el sujeto quien decide dar lugar o no al sostenimiento de esa aparición virtual. La lógica del online/offline se presenta como un disponible/no disponible para la interacción que aparenta resguardar el propio deseo y el momento para su resolución. A su vez, podríamos reconocer que la necesidad o deseo que se inscribe en el sujeto guarda relación con lo que la industria cultural ha prefigurado como posible: en tanto consumidores, deseamos lo que Grindr ofrece, e interactuamos con un Otrx en el marco de los límites que la plataforma nos permite. Deseamos y, en tanto ese deseo no se concrete, la posibilidad de tornarse aburrimiento se abre camino, sin dar lugar a nuevas asociaciones, y limitando la experiencia a lo ya conocido.

El caso de las aplicaciones de citas es explícito: el terreno del deseo aparece una vez más como un espacio sobre el cual profundizar la lógica de la mercancía. Las interacciones se ordenan a través de un usuario/consumidor que recorre con la ayuda de sus dedos o su mousse la imágenes bidimensionales que en las pantallas se ofrecen. Ello es posible si, y sólo si, la ficción de la conexión está garantizada, esta vez aún con mayor evidencia que de lo que se trata es de la mera conectividad (VAN DIJCK, 2016): la disposición de datos para navegar o un módem con acceso a Wi-Fi. La materialidad de un cuerpo ajeno se torna visible y consumible en tanto que objeto, al mismo tiempo que inaccesible. 
Revista

Debates Insubmissos

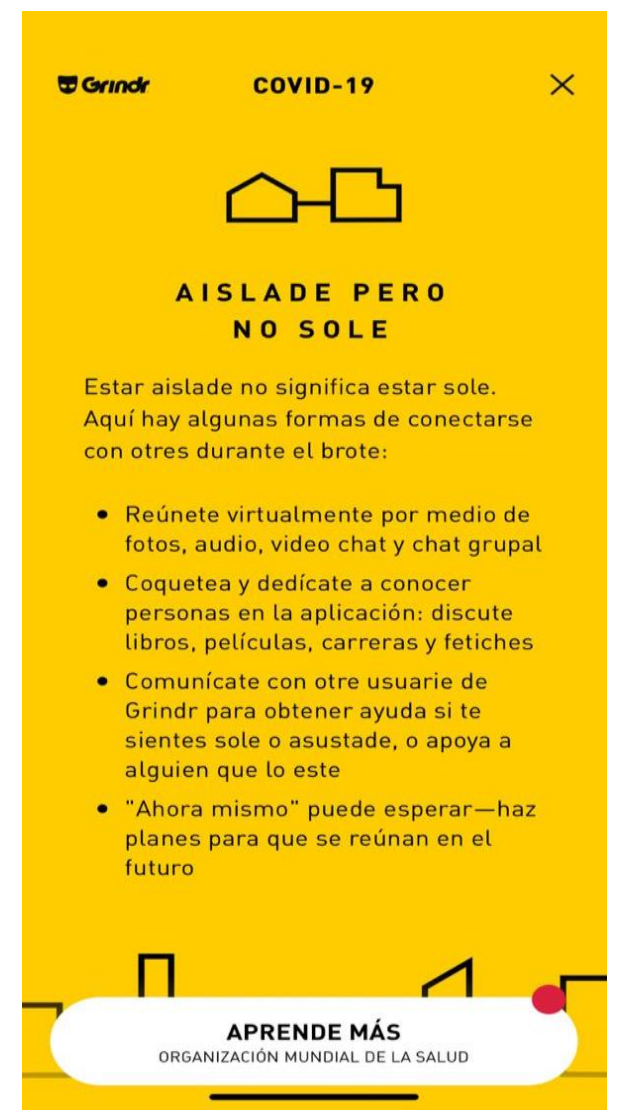

desanudar esta afirmación. Lo abordamos a continuación. ${ }^{11}$

En su mensaje, Grindr resalta que estar aislade no implica estar sole. Haciendo uso de un lenguaje no sexista, se promueve una especie de ética del autocuidado. Tanto las ideas en torno a realizar planes a futuro, como al coqueteo, aparecen hilados en un mensaje que se articula sobre una pausa que se prolonga indefinidamente. “"Ahora mismo' puede esperar- haz planes para que se reúnan en el futuro": aquí invitan a no usar la aplicación para el encuentro "urgente", modo de búsqueda posible en la aplicación a través de la categoría "ahora mismo". Nos resulta especialmente interesante este anuncio ya que expresa de un modo particular la

\footnotetext{
${ }^{11}$ Las dos imágenes corresponden al mensaje que se encuentra fijado como mensaje del "Team Grindr" en la app actualmente en Argentina.
} 
tensión entre los supuestos fines de la aplicación, el encuentro, y la distancia necesaria, condición para que la aplicación gane sentido. Frente a ese contingente "futuro" donde sea posible recuperar el encuentro físico, el encuentro urgente puede esperar. Lo que sucede en ese mientras tanto, es, lo que denominan como "coqueteo": una práctica que guarda en sí misma una irresolución. No podemos consumar la interacción carnal, porque ello significaría la irrupción del aislamiento, por tanto, la plataforma se propone como medio para garantizar una satisfacción sustitutoria: el coqueteo. Asimismo, también comienza una reconfiguración de la noción de intimidad. ¿Qué tipo de sexualidad se propone generar aún sin la presencia física de un Otrx? La seducción frente a la pantalla se ofrece sin precisiones temporales puesto que no hay especificidades en torno al tiempo de aislamiento. No obstante, se propone que la imaginación abra caminos a nuevas formas de conocer a un otrx pero se recuerda que "tú eres tu mejor pareja sexual", como un llamado a la autosuficiencia.

A través de tres links se van tejiendo vínculos del mensaje que Grindr transmite con las orientaciones de la Organización Mundial de la Salud: salud mental, enfrentamiento del estrés durante el COVID-19 y salud sexual abordada desde un blog de usuaries de PreP; con los "Tips para ligar", se convoca a que en caso de llevar a cabo un encuentro físico, se lo haga desde la reducción de riesgo y daño. El estrés, la soledad y el miedo son planteados como problemas que Grindr puede ayudar a resolver. No invita a romper la cuarentena, sino a recrear los usos de la plataforma. Se hace cargo de la coacción social, del límite externo, e imperativamente trata de encontrar las formas para conseguir la mayor cantidad de gratificaciones sustitutorias. Retoma, en lo discursivo, las voces autorizadas (gobierno nacional y provincial así como la OMS) y se auto-posiciona como un cuidador más.

La aplicación fija el mensaje, lo prioriza, y a través de éste ofrece un mundo mediante el cual esta forma de

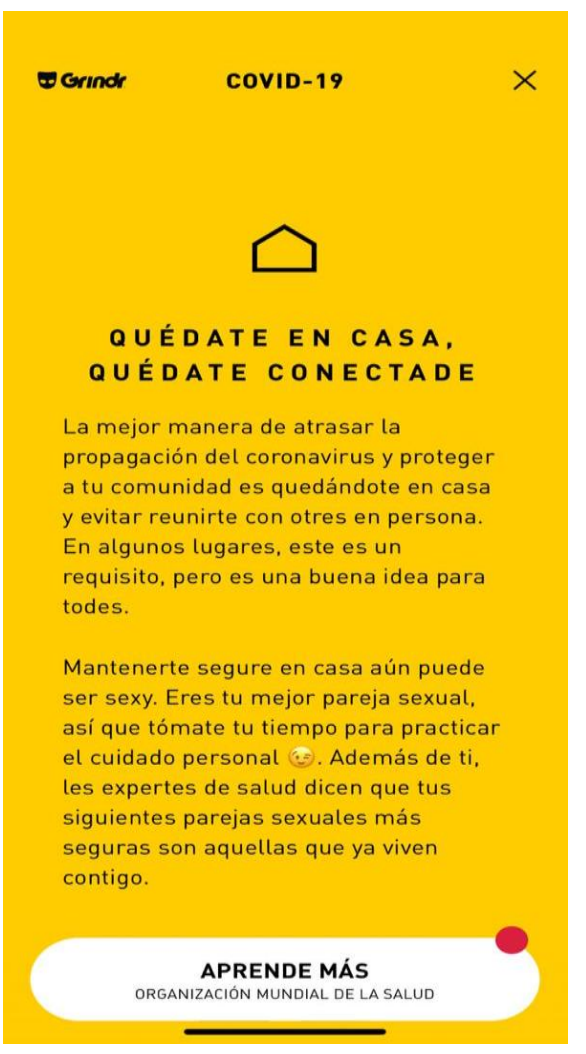


estructuración legitima las interacciones sociosexuales que propone; en ese mismo acto se garantiza consolidar el sentido propio de su existencia. A costa de esa consolidación, ¿cuáles son las huellas que deja en relación a las inscripciones en torno al Otrx? El Otrx existe ambivalentemente en esta representación en dos sentidos: como fuente de peligro para la integridad de unx, al tiempo que como víctima del miedo, la soledad y el stress. Conocerlo, ayudarlo y coquetear -todo mediado por la pantalla- siguen siendo las respuestas posibles. La garantía para todo ello se resuelve en el sostenimiento del espacio seguro: no enfrentarnos con su carne. Allí está desnuda su lógica principal: invitar al encuentro con el Otrx, pero resistir cualquier interacción que no sea virtual. Recrear nuevas formas de sexualidad, pero que siga estando mediada por la lógica del consumo de esta sociedad capitalista. Córdoba, que suele describirse como una ciudad para el encuentro, donde los espacios nocturnos de esparcimiento/salidas/vinculación funcionan los siete días de la semana, de repente haya vedados sus espacios públicos en los que se concretaban los encuentros con ese otrx. ¿Cómo ser-con-otrx en un espacios completamente virtual? ¿Cómo alterar las geografías y las sexualidades en tiempos de una pandemia que, además, deja abierta e incierta una fecha de “retorno a la normalidad”? Se habla de los no vínculos reales, ¿pero efectivamente los vínculos no presenciales no son vínculos reales? ¿Qué es lo real en un encuentro virtual donde igualmente hay un otrx manifiestx?

Sospechamos de su "quedate en casa" y "coquetear" como algo que ahora contextualmente- resultaría necesario. Esta sospecha no parte de poner en cuestión el llamado a "quedarse en casa" en sí pues, muy por el contrario, nos inscribimos políticamente en una posición que reconoce la evidencia científica de que el confinamiento ha logrado garantizar cierto control sobre el COVID-19, en tanto las medidas de distanciamiento físico “(...) pueden ayudar a disminuir la transmisión del virus; pueden reducir la carga que soporta el sistema sanitario; y pueden contribuir a que las epidemias sean gestionables, de modo que puedan adoptarse medidas específicas y orientadas" (OMS, 2020). Nuestra desconfianza cuestiona el carácter contextual que Grindr resalta. Podríamos inferir que en verdad, el llamado a no moverse es algo sobre lo cual esta plataforma ha velado desde el inicio de su lanzamiento, y le otorga todo su sentido y razón de ser: mantenernos distantes, confinades, y separades. 


\section{Debates Insubmissos}

Revista

Es, en ese marco, en el cual la noción de industria cultural se nos ofrece como herramienta para analizar desde este mensaje particular, el carácter sintomático del distanciamiento social de nuestro tiempo. Es decir, en un momento pre/confinamiento, Grindr se erigía como el espacio mediante el cual desarrollar la búsqueda y garantizar un encuentro. Esa propuesta, en los términos de Adorno y Horkheimer se presentaba en verdad como una promesa cada vez más difícil de cumplir. Utilizar la aplicación resultaba quizás más próximo al ejercicio del paseo sin consumar, a la lectura del menú de la carta, al tiempo que se proyectaba una posibilidad de cumplir el acto. Hoy, eso que antes se intentaba maquillar, aparece explícito: lo que se ofrece es un ahora mismo que puede esperar. Una pausa para planear -a través del coqueteo- una promesa a cumplir en un futuro profundamente incierto. En una sociedad de consumos urgentes y permanentes, de cuerpos-mercancías, se brinda una lista de cosas para hacer en el mientras tanto, incluso se planifica sobre qué pueden discutir lxs consumidorxs virtuales entre sí. Las leyes del mercado se inmiscuyen hasta en la intimidad de esas posibles conversaciones. En una sociedad como la cordobesa, donde conviven elementos modernos, posmodernos e, incluso, hasta premodernos, estas aplicaciones y tecnologías nos proveen alternativas a las maneras de estar cotidianas, que tienen que ver con las exigencias actuales. Todo es rápido, instantáneo e hiperproductivo: los encuentros -virtuales- sexules también.

No obstante, ante el contexto que nos plantea el desafío del distanciamiento social, Grindr invita a resolver el malestar que provoca la soledad que nos arroja la sociedad. Como planteamos anteriormente, la premisa de "quedarse en casa" es el prerrequisito de la estructuración social que le da sentido a la plataforma, y más allá de esta, es el prerrequisito de un tipo de socialidad que invade nuestra época. En este sentido, el mensaje que esgrime la aplicación nos permite dar cuenta de la expansión de la red funcional de socialización que caracteriza a la industria cultural en esta fase del capitalismo: "La industria cultural permite comprender cómo los imperativos sistémicos del capitalismo van penetrando en todas las esferas de la vida y moldean los modos de relación con el mundo." (MAISO, 2018, p. 139). Ello da cuenta de que al ser una noción que pone en cuestión no un aspecto cultural de la sociedad de la época, sino su racionalidad entera, se nos ofrece hoy como un modo posible a través del cual señalar el problema del encuentro. 
Como vimos con los teóricos críticos, y podemos recuperar junto a Maiso, los sujetos no son sólo víctimas de los imperativos sociales, sino que la industria cultural moviliza en ellos necesidades y expectativas a través del sistema de cicatrices que encarnan. Movilizando éstas, la industria cultural logra planificar

la necesidad de felicidad y la explota. La industria cultural tiene su momento de verdad en que satisface una necesidad sustancial resultante del avance social de la privación [es decir, de las crecientes renuncias que exige la supervivencia en las sociedades capitalistas, que evidencian la creciente impotencia de los sujetos ante la heteronomía que rige sus vidas, JM]; pero, por su modo de satisfacer esa necesidad, se convierte en lo absolutamente no verdadero (MAISO, 2018, p. 142 ).

Es en este sentido que Grindr, podríamos considerar, se ofrece a sus usuarixs. Movilizando ciertos aspectos de aquel sistemas de cicatrices, no sólo promete lo que cada vez en menor medida cumplirá, sino que además estructura con anticipación qué se busca, por qué se necesita, y cómo debe satisfacerse.

Otra vez, "todo el aparato erótico gira en torno al coito" (ADORNO y HORKHEIMER, 1998, p. 186) el cual sin lograr consumarse, se sostiene incalculablemente en un extenso futuro promisorio que podría eventualmente transformarse. La ley suprema, aquella negociación mediante la cual se posterga la consumación del deseo, se manifiesta en la búsqueda de un encuentro que parece diluirse en el acto mismo de su anuncio, pues solo existe como promesa.

\section{REFLEXIONES FINALES}

A lo largo de este trabajo intentamos dar cuenta de la vigencia del concepto de industria cultural para pensar las formas de estructuración social contemporáneas, y los modos en los que, sólo en apariencia, son novedosas. En este sentido, recuperando los aportes de los teóricos críticos y la relectura de éstos a través de Maiso, hemos analizado el modo de socialidad que Grindr configura, el cual en la actual situación de confinamiento se vuelve explícito. En este marco, desarrollamos la idea de que esta socialidad no tiene carácter de excepción, sino más bien que es una constante en los modos en los que el capitalismo necesita que se configuren las relaciones sociales contemporáneas.

A través del análisis de la plataforma de Grindr, pudimos evidenciar que es una 


\section{Revista \\ Debates Insubmissos}

aplicación en la cual la promesa que se esgrime no se consuma; que mediante el engaño y la movilización del sistema de cicatrices se presentan gratificaciones sustitutorias; y que la lógica de lo pornográfico está presente de manera transversal en tanto garantiza el sentido mismo de su existencia.

En ese marco las relaciones sociales que los individuos producen en y a través de Grindr, aplicación que se presenta como una aplicación sintomática de la creciente virtualización de la vida (MAISO, 2018), nos obliga a preguntarnos ¿adónde se alojan los malestares que se generan a partir del incumplimiento de la promesa de la interacción o del encuentro? Cuando se pierde la materialidad del Otrx, ¿qué se pierde? ¿qué se desvanece? Y si fuera posible, ¿qué y cómo se sustituye? Estos elementos, al ser reflexionados a partir de las categorías legadas de los teóricos críticos en su cruce con ciertas nociones del psicoanálisis, nos permitieron inferir que, si la industria cultural se presenta como el a priori de la experiencia de lo social, Grindr planifica los deseos de necesidad, y dirige de algún modo la experiencia posible. En un contexto en el cual la distancia entre las exigencias de la vida externa y la vida interna de los sujetos implica cada vez mayores renuncias por parte de los mismos para garantizar su supervivencia, se torna necesario y urgente el análisis de los malestares que de ello emergen, y sus manifestaciones en distintos ámbitos de la vida social.

La decisión de atrevernos a pensar en torno a este problema, como indicamos de manera recurrente, emergió de las inquietudes que se nos presentan a la hora de analizar ciertas prácticas sociales cotidianas que, a nuestro criterio, se evidencian de formas exacerbadas en el contexto de confinamiento actual. Sin embargo, la reflexión a la que arribamos no está desarticulada de problemas socio-culturales más amplios que, entendemos, enfrentan nuestras sociedades a escala planetaria: frente a las políticas de reificación del Otrx, en nuestra época se nos enseña y educa a no desear el cuerpo del Otrx en su materialidad, a prescindir de ello, y a aproximarnos a él a través de una pantalla, virtualmente. Un ejemplo, para nada lejano, es el que nos arroja Japón, donde año a año crece el número de personas que obtienen títulos de matrimonio (aunque sin validez oficial) con hologramas producidos por la empresa Gatebox ${ }^{12}$. Si bien distantes de

\footnotetext{
${ }^{12}$ En la página web de los desarrolladores, se presenta a Aizuma Hikari, la primera "esposa asistente virtual" del planeta. El dispositivo consta de una cápsula plástica de un poco más de medio metro de altura donde se proyecta
} 


\section{nevitate

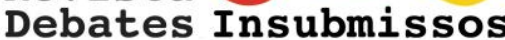

esa realidad en muchos sentidos, entendemos, es apenas cuestión de tiempo para estar atravesando de maneras más próximas experiencias semejantes. Una parte de ese camino ya lo hemos iniciado, y lo indicamos al comienzo: tele-trabajo, reuniones familiares, con amigxs, sexting, y hasta orgías virtuales, todo mediado por las pantallas.

Con ello no buscamos inscribir nuestra crítica de un modo tal que terminemos por presentar las interacciones sociales/sexuales presenciales como un ideal, puesto que bien sabemos que en el encuentro presencial con el Otrx también acontecen distancias y prácticas de displacer; lo que intentamos hasta aquí hacer fue contribuir a un ejercicio diagnóstico que al menos, nos brinde algunas herramientas tangibles para interpretar algunas dimensiones del malestar que acontece en nuestra época de virtualización creciente de la vida. Entendimos, parafraseando a Adorno y Horkheimer, que la rueda gira sobre sí misma y lo que logra la industria cultural es la pura actualización de un sistema de cicatrices que nos devuelve un malestar.

Si efectivamente este malestar está anudado a la imposibilidad del encuentro, entonces es preciso que podamos también reflexionar sobre éste, y preguntarnos: ¿Se daba ese encuentro que añoramos? por tanto, ¿lo podríamos reemplazar? Una respuesta pesimista nos devolvería: no, y al no haber pre-existido al confinamiento, tampoco puede encontrarse a través de una pantalla. Pero, nuestra hipótesis estuvo también estructurada sobre una dimensión axiológica clara: algo de eso tiene que ser falso también, y rastrearlo es una tarea política, puesto que en las interacciones pre-existentes algo del Otrx y de nosotrxs estaba aún presente.

Grindr -al igual que otras plataformas semejantes- se presenta como una mediación de la interacción, la cual nos ofrece una garantía de seguridad, una promesa de no desintegrarnos; como un servicio de seguros, las plataformas nos ofrecen una supuesta preservación propia, aunque como pura operación ideológica. Pero pensando junto a Judith Butler, "Enfrentémoslo. Los otros nos desintegran. Y si no fuera así, algo nos falta (...) el tacto, olor, el sentido, la perspectiva o la memoria del contacto del otro nos desintegran”. (2006:50) Pues, en definitiva,

holográficamente la imagen de Hikari, una anime que se encuentra conectada a los dispositivos electrónicos del hogar y el teléfono celular. El concepto que la empresa propone la presenta como "Una novia curativa, un personaje de novia que sana y crece mientras trabajas duro". Para más información https://www.gatebox.ai/hikari 
en el hallazgo del Otrx es donde se abre la posibilidad de hacernos presentes, entre nosotrxs.

\section{REFERENCIAS}

ADORNO, Theodor y HORKHEIMER, Max. Dialéctica de la ilustración. Fragmentos filosóficos. Madrid: Editorial Trotta. 1998, 303 p.

ADORNO, Theodor. Escritos sociológicos I. Madrid: Akal, 2004, 501 p.

BUTLER, Judith. Vida precaria El poder del duelo y la violencia (Traducción de Fermín Rodríguez). Buenos Aires - Barcelona - México, Paidós, 2006, 192 p.

DUARTE, Rodrigo. Industria cultural 2.0. Constelaciones. Revista de Teoría Crítica. Núm. 3, 90-117. 2011. Recuperado de http://constelaciones-rtc.net/article/view/750

MAISO, Jordi. La subjetividad dañada: Teoría Crítica y psicoanálisis. Constelaciones. Revista de Teoría Crítica. Núm. 5(5), 132-150. 2013. Recuperado de http://constelacionesrtc.net/article/view/819

MAISO, Jordi. Industria cultural: génesis y actualidad de un concepto crítico. Escritura $\mathbf{E}$ Imagen, 14, 133-148. 2018. https://doi.org/10.5209/ESIM.62767

ORGANIZACIÓN MUNDIAL DE LA SALUD. Alocución de apertura del Director

General de la OMS en la rueda de prensa sobre la COVID-19, 18 de marzo de 2020.

Recuperado de https://www.who.int/es/dg/speeches/detail/who-director-general-s-openingremarks-at-the-media-briefing-on-covid-19---18-march-2020

THEUMER, Emmanuel. Etnografía Grindr 2016 Recuperado de https://homosapienscomunicacion.wordpress.com/2016/03/31/etnografia-grindr/ VAN DIJCK, José. La cultura de la conectividad: una historia crítica de las redes sociales. Buenos Aires: Siglo XXI Editores, 2016, 304 p.

Submetido em: $29 / 06 / 2020$

Aprovado em: 16/07/2020 